\title{
Engineering Doctoral Degree Trend of Asian-American Women in the United States, 1994-2013
}

\author{
$\mathrm{Yu} \mathrm{Tao}{ }^{*}$ \\ College of Arts and Letters, Stevens Institute of Technology, 1 Castle Point on Hudson, Hoboken, NJ 07030, USA
}

\begin{abstract}
In the U.S., while Asian-Americans are overrepresented in engineering, women are underrepresented based on their share of the U.S. population. Asian-American women are unique because they belong to both groups. Using data from the Survey of Earned Doctorates, this paper compares the engineering doctorate trends of Asian-American women with those of other demographic groups and describes Asian-American women's doctoral degree trends in selected engineering subfields in two decades (1994-2013). The findings show a consistent but somewhat narrowing gender gap in earning engineering doctorates among Asian-Americans during this period. Asian-American women's share of doctorates relative to Asian-American men was lower in many years than those of African American and, to some degree, Hispanic women but higher than that of white women relative to men of their respective races/ethnicities. Furthermore, among Asian-Americans, the gender gap was smaller in chemical and materials engineering than in electrical and mechanical engineering. For Asian-American women, the influence of Asian tradition or preference for engineering for social mobility has been somewhat counteracted by the social and institutional barriers that women experience in engineering.
\end{abstract}

Keywords: Asian-American women, Asian tradition, doctoral degree trend, engineering, engineering subfields, gender differences in participation, social mobility

\section{INTRODUCTION}

In the United States (U.S.), women are well known to be underrepresented in engineering, especially at the doctoral level, based on their share of population. However, their representation has been slightly increasing over time. [1] reports that in 2011, women earned $22 \%$ of all engineering doctorates, up from $16 \%$ in 2000 . Women's representation is greater in some engineering subfields than others. Also, in 2006, women received the largest number of doctoral degrees in industrial, chemical, and materials engineering, but from 1996 to 2006, women's greatest increase was found in civil (93.1\%) and materials engineering (71.2\%) [2]. In addition, during the same time period, women also gained great increase in mechanical engineering (85\%) [3]. However, the percentage increase was mainly from temporary resident women, and the share of U.S. citizen and permanent resident women in engineering did not increase that much [2].

Among U.S. citizens and permanent residents, women of different races/ethnicities have different levels of participation in engineering. Data from the National Science Foundation (NSF) show that among all U.S. citizen and permanent resident engineering doctorate recipients in 2012, $4 \%$ were Asian and Pacific Islander women, 2\% were

*Address correspondence to this author at the College of Arts and Letters, Stevens Institute of Technology, 1 Castle Point on Hudson, Hoboken, NJ 07030, USA; Tel: (001) 201-216-5162; Fax: (001) 201-216-8245;

E-mail: ytao@stevens.edu
African American women, 2\% were Hispanic women, and $15 \%$ were White women. For comparison, $10 \%$ were Asians and Pacific Islander men; 3\% were African American men, $3 \%$ were Hispanic men, and $51 \%$ were White men [4]. More specifically, African American, Hispanic, Asian, and White women earned $47 \%, 30 \%, 48 \%$, and $29 \%$ of doctoral degrees in chemical engineering awarded to African American, Hispanic, Asian-American, and White U.S. citizens and permanent residents, respectively, in 2011. Different groups of women vary in their participation in engineering or engineering subfields relative to each other and to men of their own race/ethnicity [5].

Asian-American women are unique in that they are members of both an underrepresented group (i.e., women) and an overrepresented group (i.e., Asian-Americans) in engineering relative to their shares of U.S. population. However, not many studies focus on the trend of U.S. citizen and permanent resident Asian-American women in engineering at the doctoral level. As an effort to fill part of the gap in knowledge, this paper examines the trend of Asian-American women earning engineering doctoral degrees from 1994 to 2013 and how it differs from those of Asian-American men and other women's groups relative to their male counterparts. In addition, this paper tracks the trend of Asian-American women by subfield, including chemical, electrical, materials, and mechanical engineering. The following part of the paper is divided into four sections: 1) a review of relevant literature; 2) data and methods; 3 ) findings; and 4) discussion and conclusion. 
THEORETICAL FRAMEWORK AND LITERATURE REVIEW

\section{Women and Engineering Education}

Most studies of women in scientific fields in the U.S. aggregate science and engineering in the analysis, and only a small number and a small proportion of the studies focus exclusively on engineering. Those that focus on engineering indicate that women's low participation in engineering can be attributed to various social and institutional factors that affect their interest and retention in this field. The social factors that influence women's participation include societal stereotypes regarding engineers and family members' expectations and influence. First-year college students, especially female students, perceive personality traits that are most often associated with engineers, such as being an abstract thinker, emotionally stable, dominant, toughminded, and bold, as masculine. Engineers, along with computer and information systems specialists, compared with accountants, lawyers, physicians, and insurance agents, are more likely to be perceived as male [6].

Furthermore, family members could hinder or facilitate women's participation in engineering. [7] reveals that about a third of graduating female undergraduate engineering students interviewed at a university in the Midwest in the U.S. reported barriers from the family. More specifically, their family members could not provide assistance in science or math homework, did not support their decision to major in engineering, could not financially support them, or pushed them to choose a traditional female field such as teaching or nursing. The other two thirds report receiving parents' support and encouragement to pursue an engineering degree as well as their advice and information about careers in engineering.

In addition, role models and mentoring in the family are also influential to women in engineering. The presence of at least one person in the family (e.g., parents, siblings, aunts, uncles, grandparents) who studied engineering and/or work in an engineering-related field is significantly influencing young male and female undergraduate (the majority of the sample) and graduate students' interest in engineering and their choice of an engineering major. While no statistically significant difference is found between men with and without an engineer in the family regarding when they decided to major in engineering, such a difference is found among women. Women students with an engineer in the family than those without are more likely to have decided on engineering and the engineering subfield and less likely to be undecided on major before college [8].

Role models and mentoring in universities are also essential to women's choice of pursuing engineering education. The number of women faculty is correlated with that of women students-in engineering departments with a relatively large number and proportion of women faculty and deans who have direct contact with students through recruiting or mentoring, there are proportionately more women undergraduate students. However, mentoring is not always available to female engineering students. Without a mentor, women students have to fight social and institutional barriers alone, which prevents them from being better prepared, academically and in their future professional careers $[9,10]$.

Other institutional barriers in the U.S. include limited information about college engineering programs or engineering careers at high school [7]. In addition, in engineering departments, female students often feel excluded from informal events in which mostly men participate because the women do not have access to such opportunities. Also, women students experience the "chilly climate," or the environment in which men tend to take a dominating role and women feel unwelcome and their opinions are not appreciated or recognized, either in the classroom or the lab. Such feelings are often escalated at the graduate level, when female research assistants on a team are often taken less seriously than their male colleagues [11, 12]. Other studies support this claim by revealing that proportionately more male than female undergraduate students in computer engineering (CE) or computer science (CS) favorably evaluate CE or CS classes and teachers [13]. In addition, women students in mechanical engineering classes report lower self confidence than their male counterparts. While their final grades are not statistically significantly lower, women students are less confident in avoiding mistakes in the lab and are more likely to perceive themselves as less strong in engineering than their male classmates and believe that they are not skillful in navigation and maneuvering [14]. In short, gender role socialization in society, at home, and in school shape women's experience and influence their attainment of engineering degrees, particularly at higher levels.

\section{Minority Women and Engineering Education}

Few studies focus exclusively on minority women in engineering education in the U.S. However, some studies examine minority women's experience in science and engineering ( $\mathrm{S} \& \mathrm{E})$ as a whole. Women of different races/ethnicities may vary in their paths to $\mathrm{S} \& \mathrm{E}$ careers but share some experiences in and outside school. Interviews with Hispanic female S\&E students reveal that they have to fight with traditional female roles, such as being a mother and not working outside the home. In addition, they have to deal with the stereotype that Hispanics are not intelligent or hard-working. In order to succeed in the White- and maledominated fields, they have to deny their ethnic identity, making them distant from their friends of the same ethnicity [15]. Also, most of the interviewed Hispanic women scientists and engineers grew up in families with little or no postsecondary education and in small, closely-knit communities with no four-year colleges. They were not expected or socialized to be a scientist or engineer [16]. Nevertheless, the interviewees in both studies were able to find a teacher or a parent to be a mentor and to receive support from their spouses, friends, and academic peers.

Other research finds that African American, Hispanic, and American Indian female students in the U.S. report that they are not used to large undergraduate science and engineering classes with no direct, face-to-face interactions with professors and did not ask questions because of concerns about drawing attention to themselves in class. Additionally, some of these women students who are engaged in scientific research find that professors are 
impatient and too busy to serve as a mentor. They assume that the "chilly climate" is due to their ethnicities along with their gender [17, 18] reports that among African American and Hispanic S \&E majors, women report lower academic self-concept than their male counterparts at both freshman and senior years. While men do not experience a statistically significant decline in their self-concept over the four years, women do.

In short, minority women in engineering as well as science in the U.S. tend to be more challenged than White women and racial/ethnic minority men due to both their race and gender. Over time, minority women have increased their participation in engineering [4]. However, women's experiences of feeling excluded, alone, and discriminated against in engineering have not been significantly improved $[19,20]$.

\section{Asian-Americans' Preference for Engineering in the U.S.}

Unlike some racial/ethnic minority groups in the U.S., Asian-Americans are overrepresented in engineering. One explanation is that during and after World War II, due to a shortage of trained personnel, engineering was among the few occupations open to Asians in the United States [21]. Since then, Asians have become a major human resource supply to engineering. Other explanations include the concept of "strategic adaptation." This concept emphasizes the instrumental value instead of the intrinsic value of education. In addition, as a minority group, Asian-American youth in the U.S. tend to choose majors and occupations that can be evaluated with relatively clear and universalistic criteria, such as law, medicine, science, business ownership, and technical occupations. More importantly, these fields are financially rewarding (measured by average earnings). The universalistic evaluation of these occupations can minimize the discrimination against them, and the lucrative financial prospects provide a means of social mobility [22, 23] also reports that at the undergraduate level, compared with their White, African American, and Hispanic counterparts, AsianAmerican students tend to choose the most remunerative majors, such as engineering and business. Other studies confirm that U.S.-born or U.S.-educated engineers and computer scientists of Asian origins do not suffer from earning disadvantages relative to comparable Whites due to race [24-26]. However, highly acculturated Asian-American college students, measured by the Suinn-Lew Asian selfidentity acculturation scale, are more comfortable with the American mainstream culture and more likely to choose nontraditional fields for Asian-Americans, or fields other than engineering or computer science, than less acculturated Asian-American students [27].

Asian-American college students' choice of majors reveals gender differences. While Asian-American male students' choices of college majors do not differ significantly from those of White male students, Asian-American female students are more likely than White female students to choose non-female oriented and more lucrative majors measured by starting salaries, such as engineering and computer science [28]. In addition to the choice of college majors, gender and racial differences exist in the field of degrees received. Asian-Americans, both men and women, are more likely than their White counterparts to receive a science or engineering degree. Men are more likely than women to receive a science or engineering degree, and the gender gap holds for both Whites and Asian-Americans but is smaller among the latter than among the former. The racial difference (but not the gender difference) in the attainment of the science or engineering degree can be explained by factors related to the family, such as time spent on homework, standardized science scores, and interest in science. The results that Asian-Americans are more likely to earn science degrees than comparable Whites may be explained by AsianAmericans' connection to the Asian culture that prefers science and engineering fields. Also, the gender difference is smaller among Asian-Americans than that among Whites, which may also be accounted for by Asian-American women's but not White women's tie to the Asian tradition [29].

The studies of Asian-Americans have addressed mechanisms behind their preference for some fields, especially engineering. Most of these studies examine AsianAmericans at the baccalaureate level. As a result, we know relatively little about the trends of Asian-Americans and their gender differences in earning engineering degrees at the doctoral level.

\section{DATA AND METHODS}

This study uses data from the IPEDS Completions Survey by Race available at NSF's WebCaspar website. This data set contains information regarding doctoral degrees by race, sex, field, etc. IPEDS is a system of surveys conducted by the National Center for Education Statistics (NCES) at the U.S. Department of Education. IPEDS Completion Survey is conducted annually, with institutions participating in Title IV reporting data on degrees and other formal awards (e.g., certificates) every year by degree level (associate's, bachelor's, master's, doctor's, and firstprofessional). The IPEDS Completion data by race/ethnicity have been available since 1990. Researchers have been using IPEDS Completion Survey to understand a wide variety of issues related to postsecondary education and degrees [e.g., $30,31]$

The term "Asian-Americans" used in this paper refers to self-reported Asians or Pacific Islanders who were U.S. citizens or permanent residents when they received their doctorates. The data do not distinguish U.S. citizens from permanent residents. Also, while an examination of AsianAmericans by ethnicity (such as Chinese, Korean, Filipino, etc.) and the generation of the Asian-Americans (first generation, second generation, etc.) is desirable, the data do not allow for an investigation based on such disaggregated data. Furthermore, it is possible that individuals of Middle East origins identified themselves as Asian, but the numbers of such individuals may be small. In addition, the discussion in this paper focuses on the description of degree trends and does not render statistical differentiation of Asian-American women from other women's groups.

To understand the trends of Asian-American women and how they differ from other groups, I first examine AsianAmerican women's shares of engineering doctorates awarded to all Asian-Americans from 1994 to 2013. Then, I compare their shares with those of other women among their 


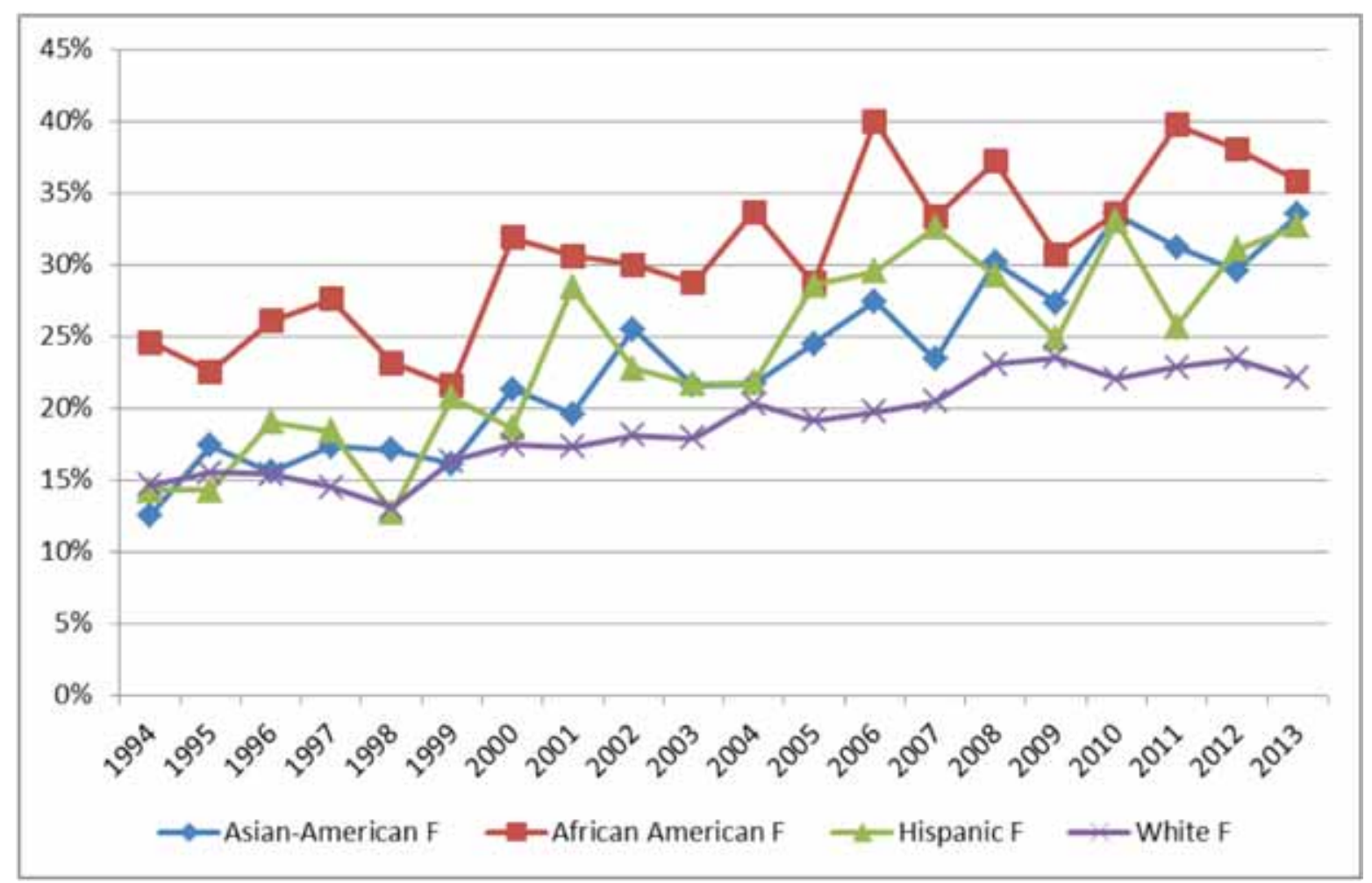

Fig. (1). Women's shares of engineering doctorates awarded to U.S. citizens and permanent residents by race/ethnicity, $1994-2013$.

respective race/ethnicity. Furthermore, I examine AsianAmerican women's representation in engineering subfields, such as chemical, electrical, materials, and mechanical engineering.

\section{FINDINGS}

Data show that Asian-American women increased the number of engineering doctoral degrees 2013 in the U.S. over time: they earned 55 engineering doctorates in 1994; 64 in 1999; 75 in 2004; 138 in 2009; and 202 in 2013 (table not shown). Their percentages also increased over time. Fig. (1) shows that despite some fluctuations, Asian-American women increased their share of engineering doctorates earned by all Asian-Americans from $13 \%$ in 1994 to $22 \%$ in 2004 and to $33 \%$ in 2013. In other words, although AsianAmericans are overrepresented in engineering relative to their share of the U.S. population [1], Asian-American women lag far behind their male counterparts in earning engineering doctorates.

In fact, the gender gap among Asian-Americans in the U.S. is similar to or even larger than that of other racial/ethnic groups. For comparison, Fig. (1) shows that in most years, African American women had a larger share (from $25 \%$ in 1994 to $36 \%$ in 2013, with the highest being $40 \%$ in 2006 and again in 2011) than other women's groups, especially White women, among their race/ethnicity. In a few years (e.g., in 1999, 2005, 2007, and 2010), Hispanic women had a similar share as African American women among their respective racial/ethnic groups. Asian-American women's share was lower than African American women's shares in most years, lower than Hispanic women's shares in some years, but higher than White women's share in most years among their respective racial/ethnic groups. White women had the lowest share (fluctuating between $13 \%$ and $23 \%$ during the period) among the four women's groups in most years, and their increase was slower but steadier than the other women's groups. In addition, each women's group increased their share of engineering doctorates awarded to their race/ethnicity over time. This finding may be explained by the fact that during the period considered, although men and women of all races/ethnicities (except White men) increased their receipt of STEM doctorates, women's increases outpaced those of men [32].

While Asian-American women in the U.S. differed from other women relative to their male counterparts, their representation also varied across engineering subfields in the 19 years with data (from 1995 to 2013). Fig. (2) reveals women's shares of doctorates among Asian-Americans in the engineering subfields with sufficient numbers of AsianAmerican women during the period. The general trend is that Asian-American women's shares increased over time in all subfields, although the growth was greater in certain subfields than others. No subfield always led in the proportion of women among Asian-Americans, but AsianAmerican women's shares were larger with less stable increase in materials and chemical engineering than in electrical and mechanical engineering in most years. It is also worth noting that from 2011 to 2013, Asian-American women's shares in chemical engineering were $43 \%-47 \%$. 


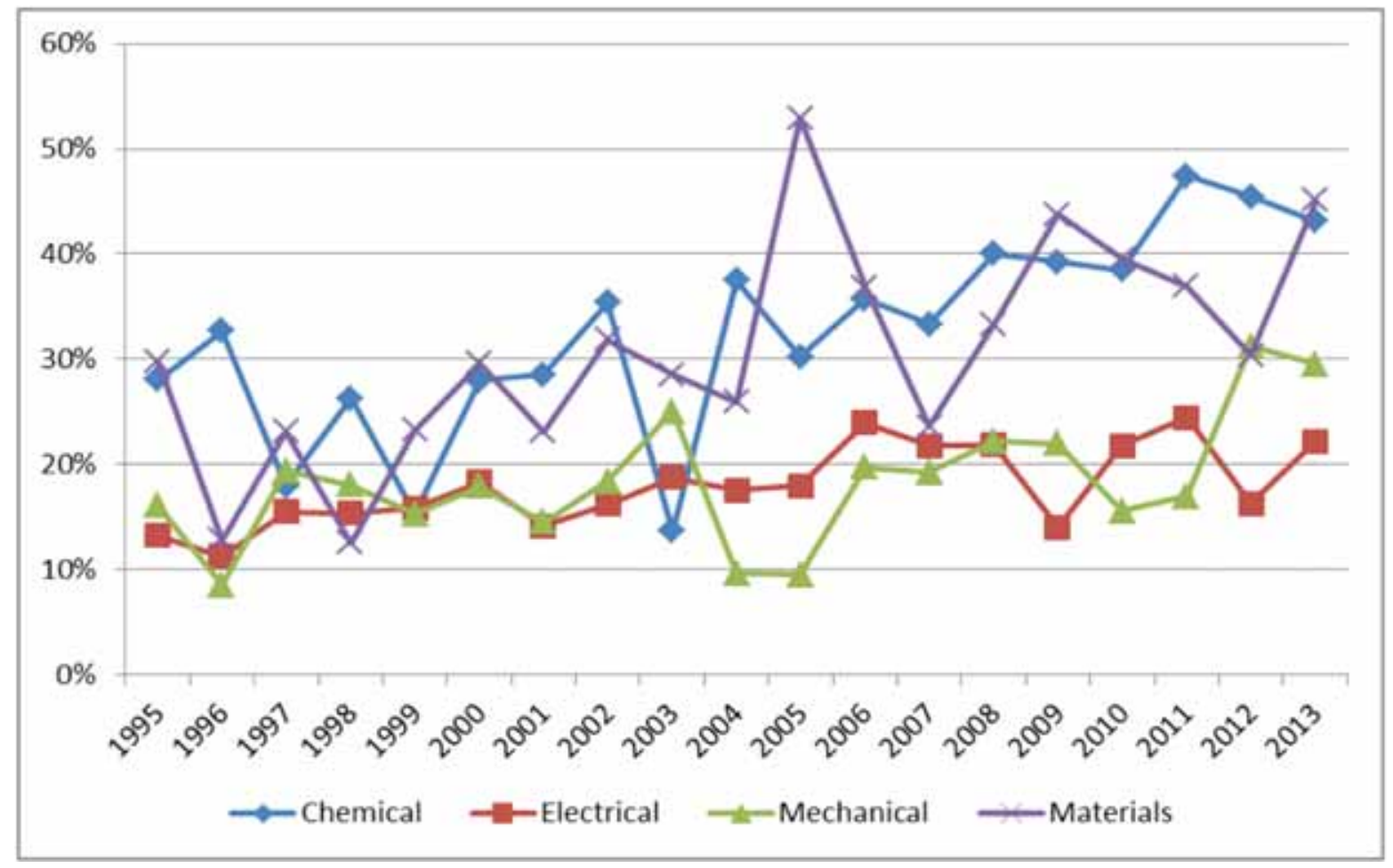

Fig. (2). Women's shares of doctorates awarded to U.S. citizen and permanent resident asian-americans in selected engineering subfields, 1995-2013.

In 2005, their share in materials engineering reached a record high of $53 \%$ (Fig. 2). Their shares in electrical and mechanical engineering were lower, but the increases in these subfields were steadier with less dramatic fluctuations than the other two.

\section{DISCUSSION AND CONCLUSION}

The findings confirm that over time, Asian-American women in the U.S. increased their participation in engineering in both numbers and percentages. Despite the growth of women in earning engineering doctorates, the findings confirm a gender difference among AsianAmericans in receiving engineering doctorates from 1994 to 2013. While Asian-American women's shares increased from $13 \%$ to $33 \%$ during the time period, Asian-American women still lagged far behind their male counterparts in earning engineering doctorates. The gender difference was also found in other racial/ethnic groups, but it was smaller among African Americans and, to some degree, Hispanics. African American women had the largest shares among the four groups in most years. However, the main reason for African American women's large share is that a relatively small number of African American men received doctoral degrees in engineering [33]. Hispanic women also had relatively high shares in some years due to the relative low level of participation of Hispanic men. White women had a lower share than other women's groups, even when White men sharply decreased their participation from the mid1990s to 2002, which indicates a more lagged progress of White women.
While Asian-American women are overrepresented in engineering relative to their share of the U.S. population, their male counterparts are overrepresented to a larger degree. For Asian-American women, the influence of Asian tradition or preference for engineering is somewhat counteracted by the influence of gender role socialization in society, at home, and in school. The social and institutional factors shaping women's choices of obtaining college degrees in engineering [e.g., 29] also shape their decisions regarding engineering doctoral degrees. In addition, the influence is likely greater at the doctoral level than at the bachelor's level because only a very selected proportion of women who are pernicious enough to have overcome social and institutional barriers at an earlier age and are prepared to overcome barriers during doctoral studies would be able to complete their doctoral education in engineering.

In regards to subfield differences, Asian-American women's shares of doctorates awarded to all AsianAmericans were larger with more dramatic increases and decreases in some engineering subfields, such as chemical and materials engineering, than others, such as mechanical and electrical engineering. These patterns are somewhat consistent with findings regarding the overall number and increases of women in engineering: women experienced greater increases in earning doctorates in chemical and materials engineering than other subfields. The finding confirms that some engineering subfields are becoming more female-oriented than others over time.

This paper presents new insights about a unique group, Asian-American women U.S. citizens and permanent 
residents in the U.S., and provides nuanced findings of this group's trend of receiving doctoral degrees compared with other groups. The increasing participation of AsianAmerican and other women could be due to more recruiting and retention efforts at the institutional or departmental level. Such an effort is shown to be effective in increasing the participation of women in engineering at the bachelor's level [34]. However, the masculine nature of engineering remains dominant, and women are still underrepresented, as evidenced in all women's groups in the two decades from 1994 to 2013. Some studies have investigated programs and institutional efforts designed to facilitate the participation of girls and racial/ethnic minorities in engineering and science at high school or in college [e.g., 35, 36]. Future studies can keep monitoring how these programs or other institutional efforts work and how their success influence women's and racial/ethnic minorities in engineering and science at the doctoral level.

Despite the contributions, this study has limitations. The data do not allow for disaggregated analysis based on Asian ethnicities (e.g., Japanese, Vietnamese, and Chinese) or show the difference between U.S. citizens and permanent residents or between Asians and Pacific Islanders. Future research can investigate ethnic differences among Asian doctoral degree recipients in engineering and science and distinguish U.S. citizens from permanent residents and Asians from Pacific Islanders. In addition, future research can investigate women's and minority women's progress in scientific fields with low proportion of women, such as computer science and physical sciences, and those with a relatively large share of women, such as biological sciences. Such investigation can also inform readers of field differences regarding women's progress in earning doctorates.

\section{CONFLICT OF INTEREST}

The author confirms that this article content has no conflict of interest.

\section{ACKNOWLEDGEMENTS}

Declared none.

\section{REFERENCES}

[1] National Science Board (NSB). Science and engineering indicators 2014. Arlington, VA: National Science Foundation 2014

[2] Ferreira MM. Trends in women's representation in science and engineering. J W Min Sci Eng 2009; 15(3): 191-203.

[3] Hoffer TB, Hess M, Welch VJ, et al. Doctorate recipients from United States universities: Summary report 2006. Chicago: National Opinion Research Center 2007.

[4] National Science Foundation (NSF). Women, minorities, and persons with disabilities in science and engineering 2014. Available from: http://www.nsf.gov/statistics/wmpd/2013/start.cfm?CFID $=17327116 \&$ CFTOKEN $=38890299 \&$ jsessionid $=\mathrm{f0}$ 301838638c31579f30407724b1a612f197 [accessed 1 Oct 2014],

[5] Atwaters S, Tao Y. Enrollment and degree awards in Chemical Engineering. In: Pearson WJ, Frehill L, McNeely CL, Eds. Advancing women in science: an international perspective. New York: Springer 2014.
[6] Cory SN, Rezaie B. Women and the engineering profession: The stereotypical engineer. J W Min Sci Eng 2008; 14(2): 141-57.

[7] Wentling RM, Camacho C. Women engineers: Factors and obstacles related to the pursuit of a degree in engineering. J W Min Sci Eng 2008; 14(1): 83-118.

[8] Mannon SE, Schreuders PD. All in the engineering family? The family occupational background of men and women engineering studies. J W Min Sci Eng 2007; 13(4): 333-51.

[9] Murphy TJ, Shehab RL, Reed-Rhoads T, et al. Achieving parity of the sexes at the undergraduate level: A study of success. J Eng Ed 2007; 96(3): 241-52.

[10] Fox MF, Sonnert G, Nikiforova I. Successful programs for undergraduate women in science and engineering: Adapting vs. adopting the institutional environment. Res Hghr Ed 2009; 50(4): 333-53.

[11] Gallaher J, Pearson F. Women's perceptions of the climate in engineering technology programs. J Eng Ed 2000; 89(3): 309-14.

[12] O'Callaghan EM, Jerger NDE. Women and girls in science and engineering: Understanding the barriers to recruitment, retention and persistence across the educational trajectory. J W Min Sci Eng 2006; 12(2-3): 209-32

[13] Varma R, Hahn H. Gender differences in students' experiences in computing education in the United States. Intl J Eng Ed 2007; 23(2): 361-67.

[14] Micari M, Pazos P, Hartmann MJZ. A matter of confidence: Gender differences in attitudes toward engaging in lab and coursework in undergraduate engineering. J W Min Sci Eng 2007; 13(3): 279-93.

[15] Brown S. The gender differences: hispanic females and males majoring in science or engineering. J W Min Sci Eng 2008; 14(2): 205-23.

[16] Ryabov I, Witherspoon P.D. Diverse pathways to the PhD: A study of women faculty in the sciences and engineering at a Hispanic serving institution. J W Min Sci Eng 2008; 14(3): 319-37.

[17] Johnson A. Graduating underrepresented African American, Latino, and American Indian students in science. J W Min Sci Eng 2007; 13(1): 1-21.

[18] Espinosa LL. The academic self-concept of African American and Latina(o) men and women in STEM majors. J W Min Sci Eng 2008; 14(2): 177-203.

[19] Taylor V. Women of color in computing. SIGCSE Bulletin 2002; 34(2): 22-23

[20] Committee on Science, Engineering, and Public Policy. Beyond bias and barriers: Fulfilling the potential of women in academic science and engineering. Washington, DC: The National Academy Press 2007.

[21] Tang J. Doing engineering: the career attainment and mobility of Caucasian, Black, and Asian-American engineers. New York: Rowman and Littlefield Publishers 2000.

[22] Xie Y, Goyette K. Social mobility and the educational choices of Asian-Americans. Soc Sci Rsch 2003; 32(3): 467-98.

[23] Goyette KA, Mullen AL. Who studies the arts and sciences? Social background and the choice and consequences of undergraduate field of study. J Hghr Ed 2006; 77(3): 497-538.

[24] Tao Y. Earnings of Asian immigrant computer scientists: The effect of degree origin. In: Cozzens S, Catalán P. Eds., Proceedings of 2009 Atlanta Conference on Science and Innovation Policy, IEEE 2009.

[25] Tao Y. Multiple disadvantages? The earnings of Asian women computer scientists in the United States, Intl J Gender Sci Tech 2010; 2(2): 136-58.

[26] Tao Y. The Earnings of Asian Engineers in the U.S.: Race, nativity, degree origin, and influences of institutional factors on human capital and earnings. J W Min Sci Eng 2011; 17(3): 225-249.

[27] Tang M, Fouad NA, Smith PL. Asian-Americans' career choices: A path model to examine factors influencing their career choices. J Voc Behvr 1999; 54(1): 142-57.

[28] Song C, Glick JE. College attendance and choice of college majors among Asian-American students. Soc Sci Quarterly 2004; 85(5): 1401-21.

[29] Hanson S, Meng Y. Science majors and degrees among AsianAmerican students: Influences of race and sex in 'Model Minority' experiences. J W Min Sci Eng 2008; 14(3): 225-52. 
[30] Shapiro DT. Modeling supply and demand for arts and sciences faculty: What ten years of data tell us about the labor market projections of Bowen and Sosa. J Hghr Ed 2001; 72 (5): 532-64.

[31] Sonnert G, Fox MF. Women, men, and academic Performance in science and engineering: The gender difference in undergraduate grade point averages. J Hghr Ed 2012; 83 (1): 73-101.

[32] National Science Board (NSB). Science and Engineering Indicators 2010. Arlington, VA: National Science Foundation 2010.

[33] National Science Foundation (NSF) Women, Minorities, and Persons with Disabilities in Science and Engineering 2010.
Available from: http://www.nsf.gov/statistics/wmpd/minwomen.cfm\#degrees [accessed 1 July 2010].

[34] Walden SE, Foor C. "What's to keep you from dropping out?" Student immigration into and within engineering. J Eng Ed 2008; 97(2): 191-205.

[35] Ohland MW, Zhang G. A study of the impact of minority engineering programs at the FAMU-FSU College of Engineering. J Eng Ed 2002; 91(4): 435-40.

[36] May GS, Chubin DE. A retrospective on undergraduate engineering success for underrepresented minority students. J Eng Ed 2003; 92(1): 27-39.

Received: October 29, 2014

(C) Yu Tao; Licensee Bentham Open.

This is an open access article licensed under the terms of the Creative Commons Attribution Non-Commercial License (http://creativecommons.org/licenses/ by-nc/3.0/) which permits unrestricted, non-commercial use, distribution and reproduction in any medium, provided the work is properly cited. 